Article

\title{
Effect of Different Raw Material Property for the Fabrication on Al/CNT Nanocomposite Using a Ball Mill with a Discrete Element Method (DEM) Simulation
}

\author{
Battsetseg Jargalsaikhan ${ }^{1,2}$, Amgalan Bor ${ }^{1}$, Jehyun Lee ${ }^{1,2}$ and Heekyu Choi ${ }^{2,3, *}$ \\ 1 Engineering Research Center (ERC) for Integrated Mechatronics Materials and Components, Changwon \\ National University, Changwon, Gyoungnam 641-773, Korea; battsetseg12@yahoo.com (B.J.); \\ amgalanbor@gmail.com (A.B.); ljh@changwon.ac.kr (J.L.) \\ 2 Graduate School of Material Science Engineering, Changwon National University, Changwon, Gyoungnam \\ 641-773, Korea \\ 3 Department of Mechanics Convergence, College of Engineering, Changwon National University, Changwon, \\ Gyoungnam 641-773, Korea \\ * Correspondence: hkchoi99@changwon.ac.kr; Tel.: +82-55-213-3841
}

Received: 6 September 2019; Accepted: 8 October 2019; Published: 10 October 2019

\begin{abstract}
Carbon nanotubes (CNTs) have received interest as an attractive reinforcing agent metal matrix composites regarded as an increase to mechanical properties of the final product. Aluminum/carbon nanotubes (Al/CNTs) nanocomposites were observed with different raw material at the optimized experimental condition. In this study, Al-based CNTs composites were three different samples, including un-milled $\mathrm{Al}$, un-milled $\mathrm{Al}$ with $\mathrm{CNTs}$, and milled $\mathrm{Al}$ with $\mathrm{CNTs}$ nanocomposites in the presence of additional CNTs with various experimental conditions while using a traditional ball mill (TBM). The particle morphology and CNT dispersions of milled composites were respectively analysed by scanning electron microscopy (SEM) and field emission scanning electron microscopy (FESEM), and the mechanical properties of the fabricated composites were tested. In each sample, CNTs were well dispersed on the surface of $\mathrm{Al}$ powder at different experimental conditions for milling in a TBM. The Al/CNTs nanocomposites were processed by compacting, sintering and rolling process. The Vickers hardness was used to characterize the mechanical properties. The hardness of Al/CNTs nanocomposites that were fabricated with milled $\mathrm{Al}$ with $\mathrm{CNT}$ was higher than the reached to in the nanocomposites prepared with the use of un-milled $\mathrm{Al}$ with CNT nanocomposites. Therefore, the discrete element method (DEM) simulation was used to complete quantitative analysis. The flow pattern, impact force, and energy at various experimental conditions are considered. The results of the simulations are compared with experimental data.
\end{abstract}

Keywords: aluminum-based matrix composites; traditional ball mill; DEM simulation; mechanical alloying

\section{Introduction}

Iijima discovered the carbon nanotubes (CNTs) in 1991 [1], and are they widely used for the fabrication of nanocomposite materials with metallic particles to improve the chemical, physical, and mechanical properties of the final products [2,3]. Choi et al. [4] studied the effect of structural and morphology of CNTs on the mechanical alloying characteristics of CNT-aluminum (Al) nanocomposite. They have studied Al powders with single-, double-, and multi-walled CNTs nanocomposites being prepared by ball mill. It can be found multi-walled CNTs (MWCNT) as reinforcements had best 
structural quality when compared to other types of the CNTs for nanocomposites. The composite of primary importance for studying the CNT dispersion under the different experimental condition and fabricating the metal-based CNT nanocomposites was owed to the excellent mechanical properties by the ball milling process $[2,5,6]$.

When considering that aluminum has a relatively low density, low strength, and other mechanical properties, among many candidate matrix materials with lightweight and high strength composites. In the Al-matrix system, more difficulty increases due to the chemical reaction between Al and CNTs forming a compound $\mathrm{Al}_{4} \mathrm{C}_{3}$, practically at the processing temperature above approximately $800 \mathrm{~K}[2,7,8]$. Many researchers have studied carbon nanotube reinforced metal matrix composites; the addition of CNTs to the metal enhances the mechanical and physical properties by the mechanical alloying process. Wang et al. investigated interactions between CNTs and Al powder for the preparation of carbon/metal composite during mechanical alloying while using ball milling, and these have improved the hardness properties of the composite [9]. Bor et al. studied different raw material physical properties while using $\mathrm{Cu} / \mathrm{CNTs}$ nanocomposites that were prepared using a planetary ball mill and investigated the effect of structural and morphology on the fabricated $\mathrm{Cu} / \mathrm{CNTs}$ nanocomposites [3]. The common uses of CNT-based nanocomposites include modern electronic devices, solar cells, automobile, aerospace, and construction industries, owing to its lighter weight and easy deformability [10,11].

The discrete element method (DEM) simulation of ball mills is very useful as a tool for analysing the impact of energy and force [12]. The discrete element method considers particles individually and examining their motion and the force of contact between particles or between particles and mill walls are modeled, according to Newton's laws of motion. The correlation between the impact energy and the grinding rate constant was estimated by DEM simulation $[13,14]$.

In this study, we fabricate $\mathrm{Al}$ with CNTs nanocomposites with better the mechanical properties while using three different raw materials (un-milled Al without CNT, un-milled Al with CNTs, specially milled Al with CNT) by a traditional ball mill (TBM) while using a DEM simulation. In the article, the DEM is used to study the motion of ball charge in ball mills and powders when it is difficult to estimate detailed results that are impact force and energy from actual experiments.

\section{Experimental}

Pure Al powders (purity: $99.8 \%$ ) with an average particle size of $44 \mu \mathrm{m}$ by Alfa Aesar and the pristine MWCNTs (the Carbon Nano-material Technology Co. Ltd., Korea) with the diameter of $20 \mathrm{~nm}$ and length of $5 \mu \mathrm{m}$ were used in this study. Figure 1 shows the morphologies of the raw materials.
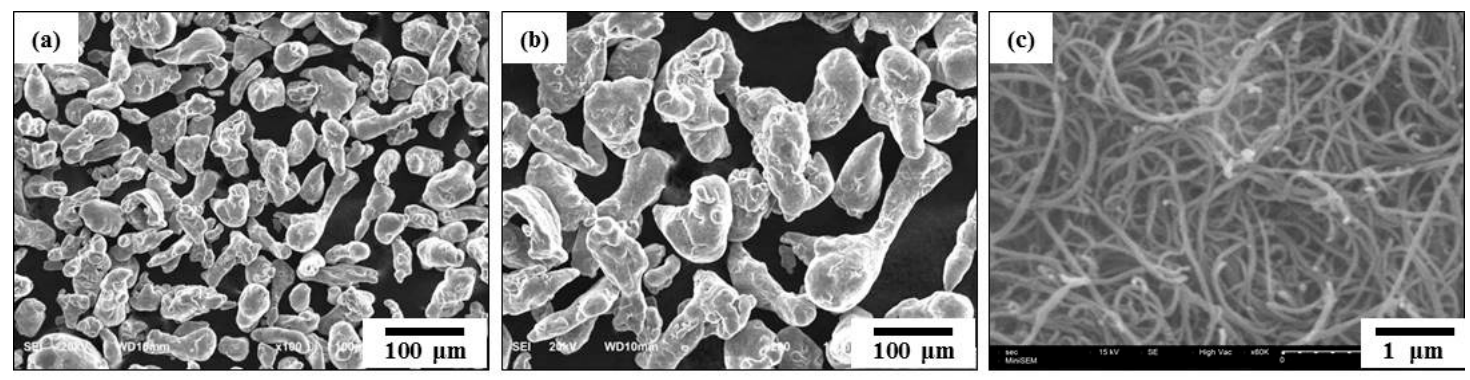

Figure 1. SEM micrographs $(\times 200)$ of $(\mathbf{a})$ the pure aluminum powder, $(\mathbf{b})$ the milled aluminum powder, and (c) the MWCNTs starting materials used.

We fabricated three different samples, including un-milled Al without CNTs powder (un-milled $\mathrm{Al}$ ), un-milled Al with CNTs nanocomposites (un-milled Al with CNTs), and milled Al with CNTs nanocomposites (milled Al with CNTs) while using a traditional ball mill with various experimental conditions. Furthermore, un-milled Al means that the pure aluminum powder and milled Al means that pure $\mathrm{Al}$ powder was milled using a traditional ball mill during $30 \mathrm{~min}$. at a rotation speed of 50 rpm. The pure $\mathrm{Al}$ and $\mathrm{Al} / \mathrm{CNT}$ nanocomposites were already studied in a wide field. In this study, 
the common point is used to milled $\mathrm{Al} / \mathrm{CNT}$ nanocomposite was compared to the un-milled $\mathrm{Al}$ and un-milled $\mathrm{Al} / \mathrm{CNTs}$ nanocomposite. Milled $\mathrm{Al}$ powder is assumed that the eventual fractured crystal structure of the $\mathrm{Al}$ particles and dislocations on the Al particles occurs; the following CNT implies improved contact between the Al particles during the ball milling process. Mechanical alloying was carried out for the prepared three different samples by a traditional ball mill at the rotation speed of 100 and $200 \mathrm{rpm}$ for milling time with 30 and $45 \mathrm{~min}$. Table 1 summarizes the experimental conditions.

Table 1. Experimental conditions using three kinds of raw material for aluminum/carbon nanotubes (Al/CNTs) nanocomposite.

\begin{tabular}{cc}
\hline \multicolumn{2}{c}{ Experimental Conditions } \\
\hline Ball milling equipment & planetary ball mill \\
Rotation speed [rpm] & 100,200 \\
Milling time [min] & 30,45 \\
Ball diameter [mm] & 5 \\
Ball powder ratio [-] & $10: 1$ (fixed) \\
Ball filling ratio [-] & $0.3(\mathrm{fixed})$ \\
Amount of CNTs & $1 \mathrm{wt} \%$ \\
Material of media & zirconia \\
Temperature & room temperature \\
\hline
\end{tabular}

The fabricated composites were examined while using scanning electron microscopy (SEM) (JSM-6510, JEOL, Japan) for powder morphology and field emission scanning electron microscopy (FESEM) (CZ/MIRAI LMH, Tescan, Czech) for the dispersion of CNTs on the surface of Al powder. After milling, the fabricated composites are pressed in dies under high pressure to form them into the shape of $15 \mathrm{~mm}$ of height and $5 \mathrm{~mm}$ of depth while using 1.5 tons compacting machine made by Haji Engineering, Korea at room temperature. Subsequently, the conventional sintering of Al/CNTs composites was performed while using a vacuum tube machine, Haji Engineering, Korea. The sintering experimental conditions are shown in Table 2. Sintered Al/CNTs nanocomposites were rolled at room temperature by rolling machine, hardness has been observed.

Table 2. Experimental conditions of sintering.

\begin{tabular}{cc}
\hline \multicolumn{2}{c}{ Sintering Experimental Conditions } \\
\hline Temperature $\left[{ }^{\circ} \mathrm{C}\right]$ & 500 \\
Change time $[\mathrm{min}]$ & 150 \\
Maintenance time $[\mathrm{min}]$ & 240 \\
\hline
\end{tabular}

Table 3 gives the DEM simulation in the traditional ball mill was analyzed in the simulation condition.

Table 3. Calculation condition for simulation.

\begin{tabular}{cc}
\hline \multicolumn{1}{c}{ Parameters } \\
\hline Types of ball & Zirconia ball \\
Density [kg/m ${ }^{3}$ ] & 6220 \\
Young modulus [MPa] & 200,000 \\
Possion's ratio & 0.3 \\
Dynamic friction coefficient [-] $\quad$ ball-ball & 0.5 \\
Rolling friction coefficient [-] & 0.1 \\
Thermal conductivity [W/(m K)] & 0.02 \\
Rotation speed [rpm] & 3.5 \\
Ball diameter [mm] & $100 ; 200$ \\
Number of balls & 5 \\
Ball filling ratio [-] & 113 \\
Simulation time [sec] & 0.3 \\
\end{tabular}


The DEM simulation used in this work changed experimental condition is the milling rotation speed. The other parameters of simulation conditions are fixed. The ball mill is modeled by a discrete element method using the software package in the Samadii ${ }^{\mathrm{TM}} / \mathrm{DEM}$. The simulation time of three seconds represents the steady-state of the simulation, which is the reason the simulation experiment is short. It does not make sense to simulate long.

\section{Results and Discussion}

Figure 2 shows the SEM photographs of un-milled Al without CNT powders was milled at the rotation speed of $100 \mathrm{rpm}$ with $30 \mathrm{~min}$. and $45 \mathrm{~min}$. (Figure 2a,b) and rotation speed of $200 \mathrm{rpm}$ with $30 \mathrm{~min}$. and $45 \mathrm{~min}$. (Figure 2c,d) by ball diameter of $5 \mathrm{~mm}$. At first, we fabricated un-milled $\mathrm{Al}$ without CNT dramatically that did not change in morphology at $100 \mathrm{rpm}$ and $200 \mathrm{rpm}$ at different grinding times. The particle size was slightly increased in this experimental condition. It is for this reason that the low energy ball mill gave low energy impact to the powder. Choi et al. [15] discussed particle size does not change effectively for low rotation speed. In addition, a low rotation speed has less effect on powder crystallization due to collisions between particles in the ground powder at low rotation speed having less impact energy [16]. Figure 3 shows the change of particle morphology of un-milled Al with CNT composite at the rotation speed of $100 \mathrm{rpm}$ and $200 \mathrm{rpm}$ for different milling times of $30 \mathrm{~min}$. and $45 \mathrm{~min}$. while using a ball size of $5 \mathrm{~mm}$. The particle morphology of un-milled Al with CNT nanocomposites was effectively not changed and slightly increased particle size. The SEM photographs milled Al with CNTs nanocomposites was milled experimental conditions with the rotation speed of $100 \mathrm{rpm}$ and $200 \mathrm{rpm}$, ball diameter of $5 \mathrm{~mm}$, and milling times of $30 \mathrm{~min}$. and $45 \mathrm{~min}$., as shown in Figure 4. Milled Al with CNTs nanocomposites did not change the morphology of particle and increases a particle size. The mechanical alloying process has two kinds of the process, when considering one is the cold-working of the powders that lead to a reduction in ductility and fracturing of the particles, the other is cold-welding of particles, which trends to increase the particle size [17].
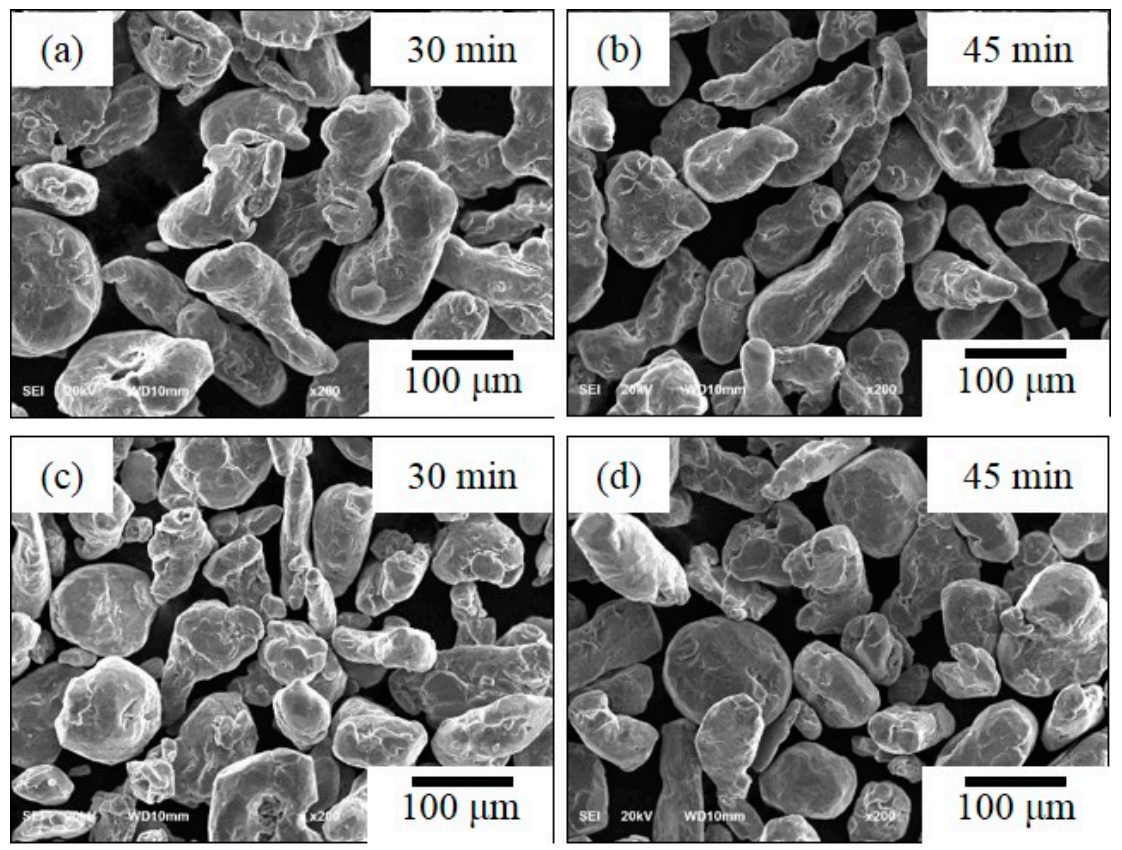

Figure 2. SEM photographs $(\times 200)$, un-milled Al without CNT showing a rotation speed of $(\mathbf{a}, \mathbf{b}) 100$ rpm and (c,d) $200 \mathrm{rpm}$ at different milling time of $30 \mathrm{~min}$ and $45 \mathrm{~min}$. 

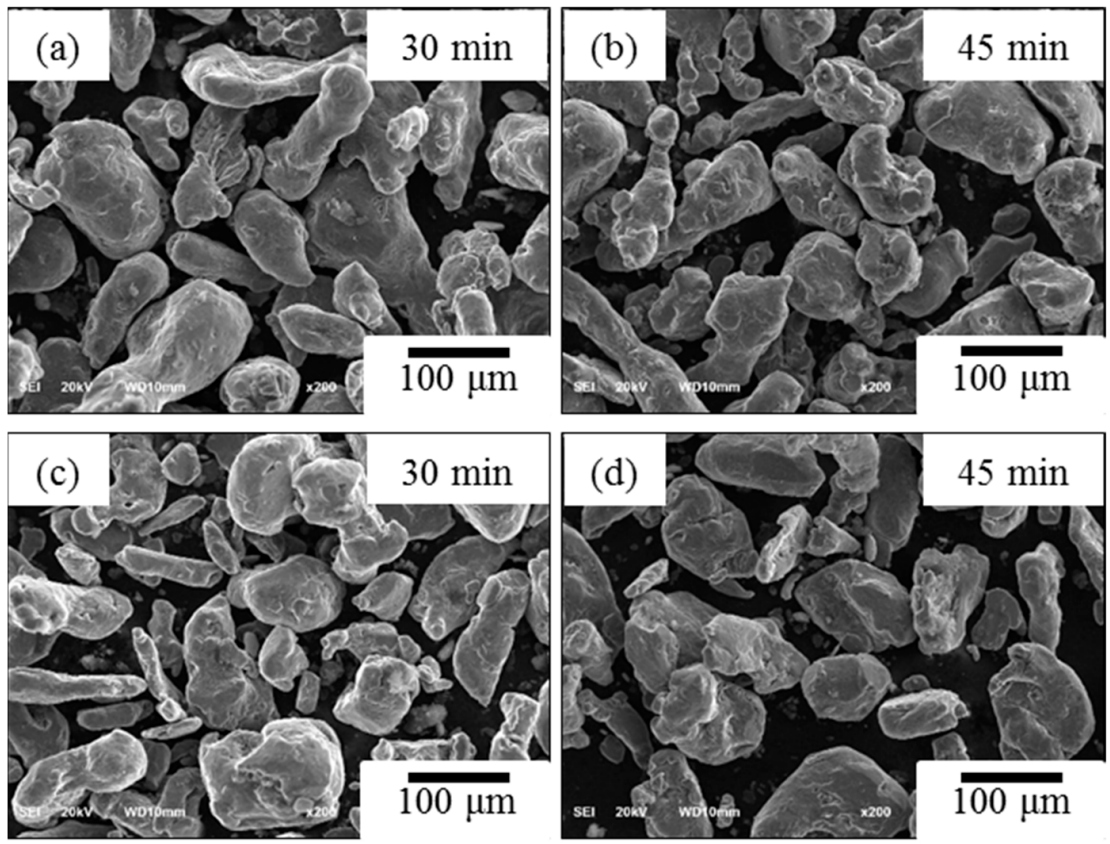

Figure 3. SEM photographs $(\times 200)$, un-milled Al with CNT showing a rotation speed of $(\mathbf{a}, \mathbf{b}) 100 \mathrm{rpm}$ and (c,d) $200 \mathrm{rpm}$ at different milling time of $30 \mathrm{~min}$ and $45 \mathrm{~min}$.
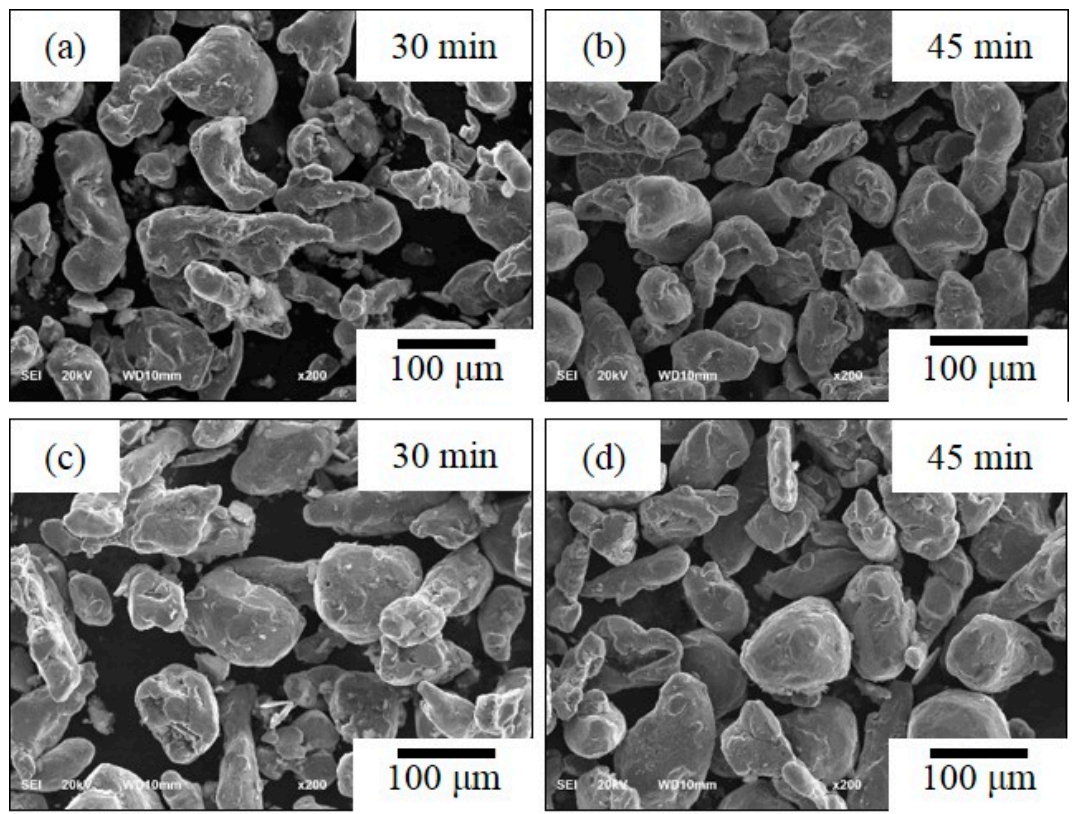

Figure 4. SEM photograph $(\times 200)$, milled Al with CNT showing a rotation speed of $(\mathbf{a}, \mathbf{b}) 100 \mathrm{rpm}$ and (c,d) $200 \mathrm{rpm}$ at different milling time of $30 \mathrm{~min}$ and $45 \mathrm{~min}$.

We compared CNTs dispersion of un-milled Al with CNTs and milled Al with CNTs nanocomposites by FESEM results under the same experimental conditions.

The FESEM micrographs in Figure 5 show the microstructures that were obtained when the un-milled $\mathrm{Al}$ with CNTs nanocomposites is processed with different rotation speeds are $100 \mathrm{rpm}$ and $200 \mathrm{rpm}$ and the milling times are $30 \mathrm{~min}$. and $45 \mathrm{~min}$. As the micrographs show, CNTs spread over the surface of Al powder during (Figure 5a) $30 \mathrm{~min}$. at a rotation speed of (Figure 5a,b) $100 \mathrm{rpm}$ and adhered and spread over the surface after (Figure 5b) $45 \mathrm{~min}$. In the case of (Figure 5c,d) $200 \mathrm{rpm}$, the CNT coating that was obtained after (Figure 5c) $30 \mathrm{~min}$. of milling showed to be well dispersed to that obtained after (Figure 5d) $45 \mathrm{~min}$. 

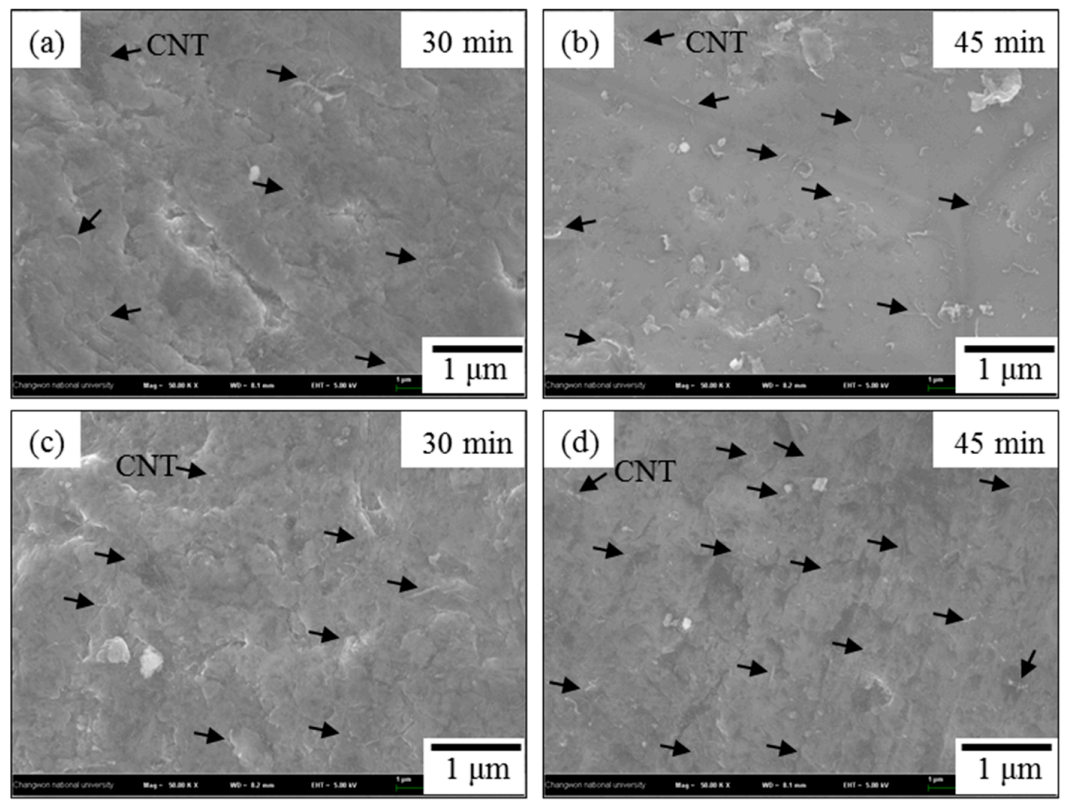

Figure 5. Field emission scanning electron microscopy micrographs $(\times 50,000)$ of un-milled Al with CNT at (a,b) $100 \mathrm{rpm}$ and (c,d) $200 \mathrm{rpm}$ for various milling times with $30 \mathrm{~min}$ and $45 \mathrm{~min}$. (black arrows indicate the CNTs).

Figure 6 shows the FESEM micrographs of CNTs dispersed in the surface of the milled Al. It can be seen that CNTs are adhered and well dispersed on the surface of milled Al with the rotation speed of $100 \mathrm{rpm}$ at different milling times are (Figure 6a) $30 \mathrm{~min}$. and (Figure 6b) $45 \mathrm{~min}$. After milling with the rotation speed of (in Figure $6 \mathrm{c}, \mathrm{d}$ ) $200 \mathrm{rpm}$, the nanotubes are strongly attached and uniformly embedded in the Al surface or underlying CNTs under the mechanical force of milling balls.
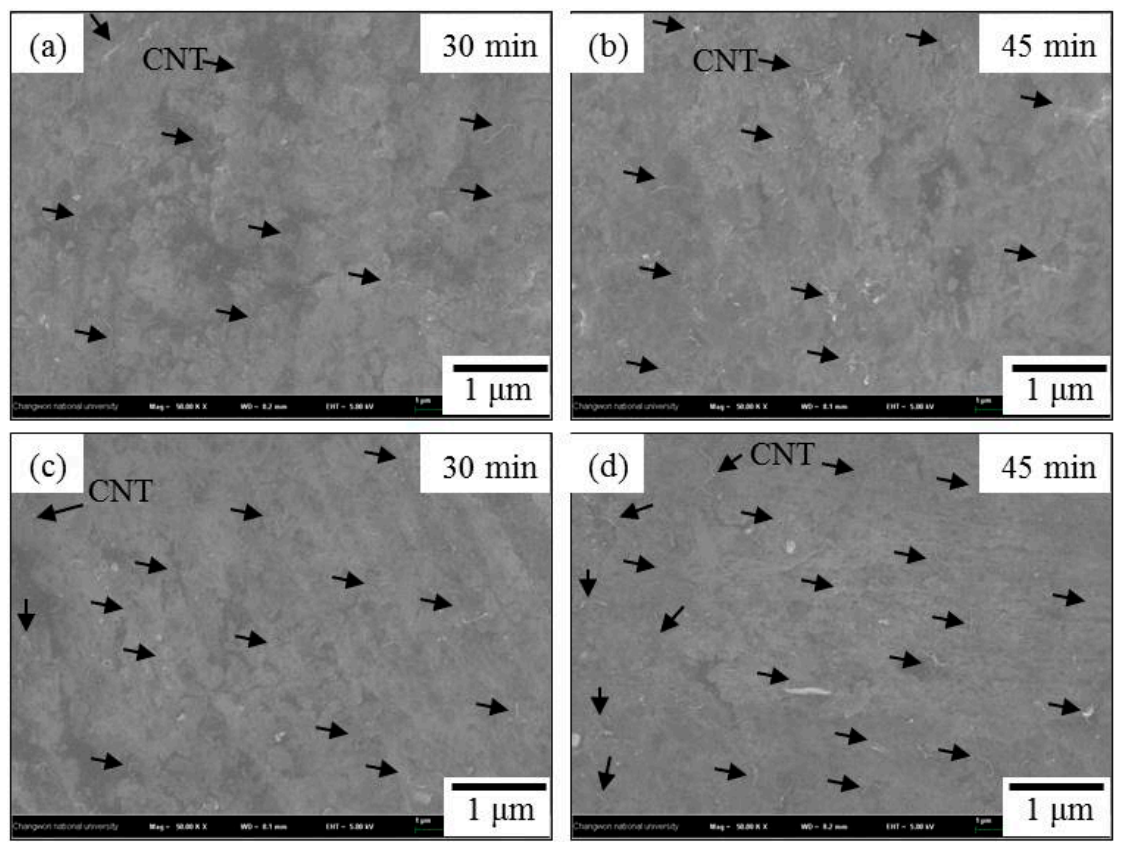

Figure 6. FESEM micrographs $(\times 50,000)$ of milled Al with CNT at $(\mathbf{a}, \mathbf{b}) 100 \mathrm{rpm}$ and $(\mathbf{c}, \mathbf{d}) 200 \mathrm{rpm}$ for various milling times with $30 \mathrm{~min}$ and $45 \mathrm{~min}$. (black arrows indicate the CNTs).

When compared with un-milled Al with CNTs, milled Al with CNTs nanocomposites has a significant amount of absorbed CNTs (the increasing area of the wrinkled imprint on the Al surface) 
and CNTs were better dispersed on the surface at long milling time. The collisions between powders at low rotation speed have less impact energy on the grinding media [2]. The essential factor in based on a metal matrix of CNTs particle coating is subjecting the sample to low-energy grinding ball impact force over a longer time, rather than higher force over a short time. That is the influence of the contact number during the milling process is greater than that of the impact power of the milling ball. Bor et al. [18] studied, by TBM, the best CNTs dispersions were for $\mathrm{Cu} / \mathrm{CNTs}$ nanocomposites at a longer milling time at low rotation speed.

We prepared from Al powder and Al-CNTs powder mixtures that measured the hardness of their samples by the Vickers hardness test. The hardness of samples, including un-milled Al, un-milled $\mathrm{Al}$ with CNTs, and milled Al with CNTs nanocomposites, are compared as experimental conditions of the rotation speed of $100 \mathrm{rpm}$ and $200 \mathrm{rpm}$ or milling times are $30 \mathrm{~min}$. and $45 \mathrm{~min}$. while using a traditional ball mill.

The milled Al with CNTs nanocomposites is exactly increased to compare to others. Figure 7 shows the Vickers hardness results. The milled Al with CNTs nanocomposites hardness continues to increase with the rotation speed of $100 \mathrm{rpm}$ and $200 \mathrm{rpm}$ that hardness substantially higher than those of the other samples processed for the same time, reflecting the uniform dispersion of CNTs in the Al matrix. It is now needed to consider the reason for an improved mechanical property to the milled $\mathrm{Al}$ using for composite. Choi et al. [4] studied the composite samples of MWCNT-Al powder mixture, and their hardness increased with longer mechanical alloying time and showed hardness higher than that compared to other samples. The hardness test is an easy and simple method to measure the mechanical properties of materials. In the future study, we will study electrical, thermal conductivity, and high tensile strength.

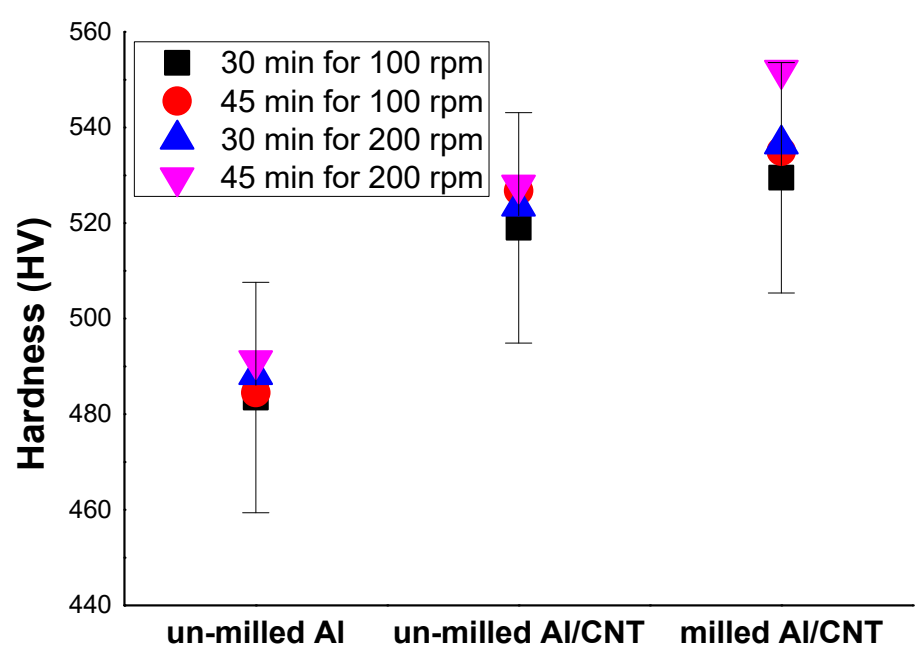

Figure 7. Results from Vickers hardness test. As a comparison, un-milled Al, un-milled Al with CNTs, and milled $\mathrm{Al}$ with CNTs under different milling time and rotation speed by a traditional ball mill.

Figure 8 shows a comparison between the results of observing the actual ball motion, which takes a camera and the results of analyzing the ball movement by simulation according to different rotation speeds are $100 \mathrm{rpm}$ and $200 \mathrm{rpm}$ while using the zirconia ball. The actual and simulated results show a similar trend between the experimental and simulated movements.

We undertook quantitative analysis from DEM simulation, the impact force, and cumulative impact energy of the balls in a traditional ball mill with a different rotation speed could be obtained. DEM solves Newton's equations of motion to resolve particle motion and uses a contact law to resolve inter-particle contact force [19]. Figures 9 and 10 show two different rotation speeds of milling simulated. Note that all energy between balls and wall of the pot, among balls themselves, are considered. The results suggest that the material receives more strong impact from the balls for 200 
rpm. In the simulation experiment, the sample does not get in the pot is regardless of the experimental results. The actual and simulated experiment results are potentially estimated, not matches.

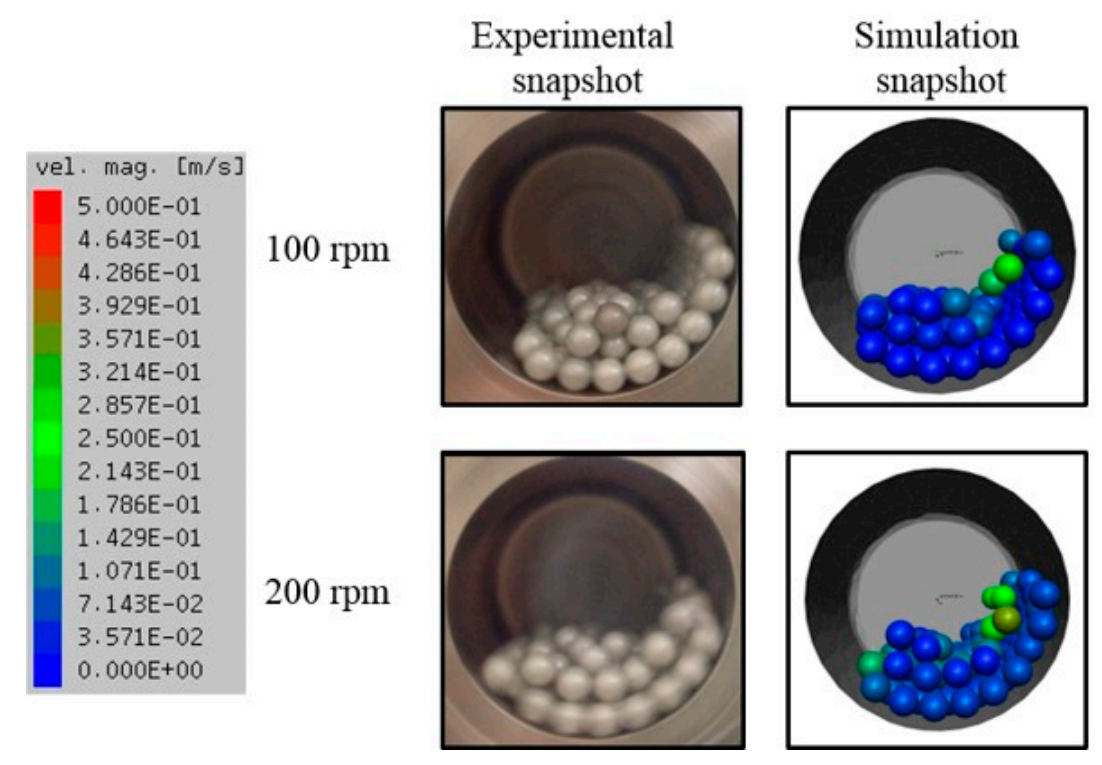

Figure 8. Actual photograph and simulation snapshot of the media motion results show from DEM simulation.

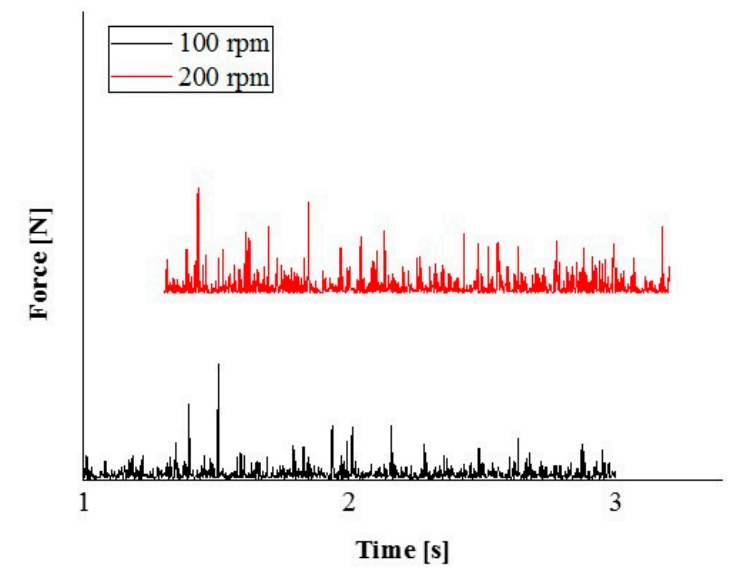

Figure 9. Impact force spectra of the balls in a traditional ball mill at different milling rotation speeds.

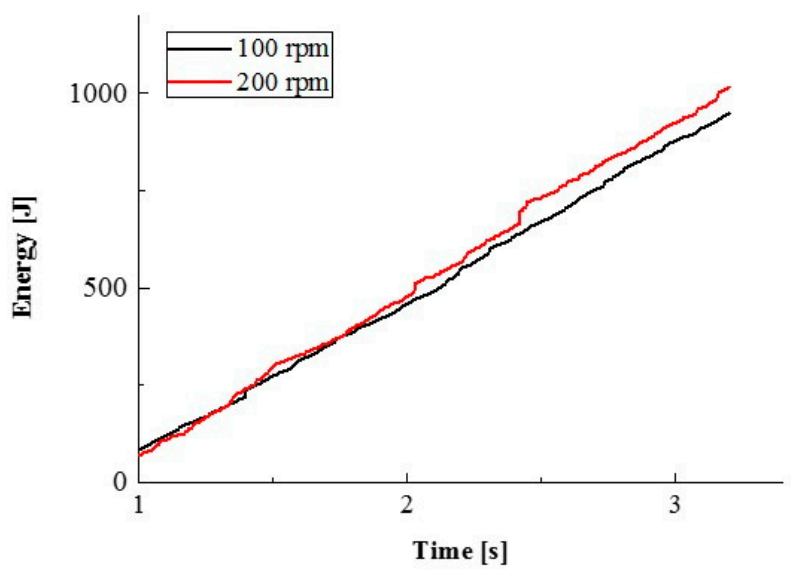

Figure 10. Cumulative impact energy distribution of the balls in a traditional ball mill at different milling rotation speeds. 


\section{Conclusions}

In this study, we successfully fabricated three different samples of Al with CNT nanocomposites by observing the effect of various conditions on the physical properties.

SEM results show that the particle morphology of Al powder was slightly increased with increasing rotation speed and milling time. The particle morphology was changed from an irregular type to kind of spherical type at $200 \mathrm{rpm}$ in a milled $\mathrm{Al}$ with CNTs nanocomposites.

The FESEM results of fabricated nanocomposites show that CNTs were homogeneously dispersed over on the surface of the $\mathrm{Al}$ powder as well as successfully dispersed on the surface of $\mathrm{Al}$ powder milled $\mathrm{Al}$ with CNTs than un-milled Al with CNTs.

The hardness of fabricated samples found that the hardness of the milled Al with CNTs was dramatically improved when compared to un-milled Al with CNTs under the same experimental conditions.

The results of quantitative analysis from DEM simulation show a total force and energy that is not found in actual experiments.

Author Contributions: Conceptualization, H.C.; Methodology, B.J., H.C. and A.B.; Software, B.J; Validation, H.C. and A.B.; Formal Analysis, B.J.; Investigation, B.J.; Data Curation, H.C., B.J. and A.B.; Writing-Original Draft Preparation, B.J.; Writing-Review \& Editing, B.J. and A.B.; Supervision, H.C.; Project Administration, J.L.; Funding Acquisition, J.L.

Funding: This work was supported by the National Research Foundation of Korea (NRF) grant funded by the Korea government (MSIP) (2018R1A5A6075959).

Conflicts of Interest: The authors declare no conflict of interest.

\section{References}

1. Iijima, S. Helical microtubules of graphitic carbon. Nature 1991, 354, 56-58. [CrossRef]

2. Deng, C.F.; Wang, D.Z.; Zhang, X.X.; Li, A.B. Processing and properties of carbon nanotubes reinforced aluminum composites. Mater. Sci. Eng. A 2007, 444, 138-145. [CrossRef]

3. Bor, A.; Ichinkhorloo, B.; Uyanga, B.; Lee, J.; Choi, H. Cu/CNT nanocomposite fabrication with different raw material properties using a planetary ball milling process. Powder Technol. 2018, 323, 563-573. [CrossRef]

4. Choi, H.; Wang, L.; Cheon, D.; Lee, W. Preparartion by mechanical alloying of Al powders with single-, double-, and multi-walled carbon nanotubes for carbon/metal nanocomposites. Compos. Sci. Technol. 2013, 74, 91-98. [CrossRef]

5. Pérez-Bustamante, R.; Pérez-Bustamante, F.; Estrada-Guel, I.; Licea-Jiménez, L.; Miki-Yoshida, M.; Martínez-Sánchez, R. Effect of milling time and CNT concentration on hardness of CNT/Al2024 composites produced by mechanical alloying. Mater. Charact. 2013, 75, 13-19. [CrossRef]

6. Liu, Z.Y.; Xu, S.J.; Xiao, B.L.; Xue, P.; Wang, W.G.; Ma, Z.Y. Effect of Ball-Milling time on mechanical properties of carbon nanotubes reinforced aluminum matrix composites. Compos. Part A Appl. Sci. Manuf. 2012, 43, 2161-2168. [CrossRef]

7. Ci, L.; Ryu, Z.; Jin-Phillipp, N.Y.; Rühle, M. Investigation of the interfacial reaction between Multi-Walled carbon nanotubes and aluminum. Acta Mater. 2006, 54, 5367-5375. [CrossRef]

8. Khalid, F.A.; Beffort, O.; Klotz, U.E.; Keller, B.A.; Gasser, P.; Vaucher, S. Study of microstructure and interfaces in an Aluminium- $\mathrm{C}_{60}$ composite material. Acta Mater. 2003, 51, 4575-4582. [CrossRef]

9. Wang, L.; Choi, H.; Myoung, J.; Lee, W. Mechanical alloying of Multi-Walled carbon nanotubes and aluminium powders for the preparation of carbon/metal composites. Carbon 2009, 47, 3427-3433. [CrossRef]

10. Maiti, A.; Laha, T. Study of distribution of Carbon nanotube in Al-CNT nanocomposite synthesized via Spark-Plasma sintering. IOP Conf. Ser. Mater. Sci. Eng. 2018, 388, 012014. [CrossRef]

11. Ma, K.; Wen, H.; Hu, T.; Topping, T.D.; Isheim, D.; Seidman, D.N.; Lavernia, E.J.; Schoenung, J.M. Mechanical behavior and strengthening mechanisms in ultrafine grain Precipitation-Strengthened aluminum alloy. Acta Mater. 2014, 62, 141-155. [CrossRef]

12. Teufelsbauer, H.; Wang, Y.; Pudasaini, S.P.; Borja, R.I.; Wu, W. DEM simulation of impact force exerted by granular flow on rigid structures. Acta Geotech. 2011, 6, 119-133. [CrossRef] 
13. Iwasaki, T.; Yabuuchi, T.; Nakagawa, H.; Watano, S. Scale-Up methodology for tumbling ball mill based on impact energy of grinding balls using discrete element analysis. Adv. Powder Technol. 2010, 21, 623-629. [CrossRef]

14. Yin, Z.; Peng, Y.; Li, T.; Wu, G. DEM Investigation of mill speed and lifter face angle on charge behavior in ball mills. IOP Conf. Ser. Mater. Sci. Eng. 2018, 394, 032084. [CrossRef]

15. Choi, H.; Bor, A.; Sakuragi, S.; Lee, J.; Lim, H.-T. The grinding behavior of ground copper powder for Cu/CNT nanocomposite fabrication by using the dry grinding process with a High-Speed planetary ball mill. J. Korean Phys. Soc. 2016, 68, 147-153. [CrossRef]

16. Battsetseg, J. Al/CNT nanocomposite fabrication on different property of raw material using media milling process with DEM simulation. Master's Thesis, Changwon National University, Changwon, Korea, 2018.

17. Esawi, A.; Morsi, K. Dispersion of carbon nanotubes (CNTs) in aluminum powder. Compos. Part A 2007, 38, 646-650. [CrossRef]

18. Bor, A.; Jargalsaikhan, B.; Lee, J.; Choi, H. Surface coating copper powder with carbon nanotubes using traditional and stirred ball mills under various experimental conditions. Particuology 2018, 40, 177-182. [CrossRef]

19. Weerasekara, N.S.; Liu, L.X.; Powell, M.S. Estimating energy in grinding using DEM modelling. Miner. Eng. 2016, 85, 23-33. [CrossRef]

(C) 2019 by the authors. Licensee MDPI, Basel, Switzerland. This article is an open access article distributed under the terms and conditions of the Creative Commons Attribution (CC BY) license (http://creativecommons.org/licenses/by/4.0/). 